REPLY TO LETTER

\title{
Practical aspects of etomidate use in the management of hypercortisolaemia
}

\author{
Veronica A Preda and Ashley B Grossman \\ Oxford Centre for Diabetes, Endocrine and Metabolism (OCDEM), Churchill Hospital, Oxford OX3 7LE, UK \\ (Correspondence should be addressed to A B Grossman; Email: ashley.grossman@ocdem.ox.ac.uk)
}

\begin{abstract}
We appreciate the letter from of Dr Soh et al. regarding our review on the use of etomidate in the treatment of Cushing's syndrome. We note that in their experience, our recommended dose regimen of $2.5 \mathrm{mg} / \mathrm{h}$ or thereabouts appears to be a safe and effective starting dose in most patients, and we note the utility and ease of use of the lipid formulation and its relative freedom from side effects compared with the more commonly used propylene glycol formulation; these are very helpful comments. Their experience in treating a further four patients is indeed further evidence of the usefulness of this agent.
\end{abstract}

European Journal of Endocrinology 167729

\section{Dear Sir,}

We appreciate the letter from of Dr Soh et al. regarding our review on the use of etomidate in the treatment of Cushing's syndrome (1). We note that in their experience, our recommended dose regimen of $2.5 \mathrm{mg} / \mathrm{h}$ or thereabouts appears to be a safe and effective starting dose in most patients, and we note the utility and ease of use of the lipid formulation and its relative freedom from side effects compared with the more commonly used propylene glycol formulation; these are very helpful comments. Their experience in treating a further four patients is indeed further evidence of the usefulness of this agent.

They also draw attention to their use of etomidate in a specialist ward setting as opposed to our general recommendation of an intensive or critical care unit. While sedation does not appear to be a particular hazard at the dose recommendations we have both outlined, they emphasise, as did we, that patients must be closely monitored both in terms of observations and frequent blood sampling. This may be possible in a specialist ward with experience of the drug, but we remain somewhat concerned that the very occasional use of etomidate in departments with less experience and with only very occasional usage of etomidate may not have such facilities readily available. Clearly, at Barts with extensive experience in the diagnosis and treatment of Cushing's syndrome, close monitoring in a ward with a specialist team is entirely appropriate. However, we would just caution on the use of etomidate in a general ward where such expertise and manpower may be less in evidence.

\section{Declaration of interest}

The authors declare that there is no conflict of interest that could be perceived as prejudicing the impartiality of the research reported.

\section{Funding}

This research did not receive any specific grant from any funding agency in the public, commercial or not-for-profit sector.

\section{References}

1 Preda VA, Sen J, Karavitaki N \& Grossman AB. Therapy in endocrine disease: etomidate in the management of hypercortisolaemia in Cushing's syndrome: a review. European Journal of Endocrinology 2012167 137-143. (doi:10.1530/EJE-12-0274)

Received 23 August 2012

Accepted 29 August 2012 